\title{
Gastric Pylorus Carcinoma In Situ AJCC v6 and $v 7$
}

National Cancer Institute

\section{Source}

National Cancer Institute. Gastric Pylorus Carcinoma In Situ A/CC v6 and v7. NCI

Thesaurus. Code C4431.

Stage 0 includes: Tis, N0, M0. Tis: Carcinoma in situ: intraepithelial tumor without invasion of the lamina propria. N0: No regional lymph node metastasis. M0: No distant metastasis. (AJCC 6th and 7th eds.) 